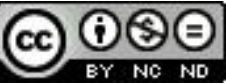

\section{Saúde e Números: uma parceria de sucesso}

\section{Health and Numbers: a successful partnership}

\author{
Paula Reis de Miranda* \\ Eliane Scheid Gazire**
}

\begin{abstract}
Resumo
Perante a recente inserção da Educação de Jovens e Adultos na rede federal de Educação Profissional e Tecnológica, por meio da implantação do PROEJA - Programa de Integração à Educação Básica na Modalidade Educação de Jovens e Adultos nos Institutos Federais de Educação, Ciência e Tecnologia, percebeu-se a necessidade de investigar as possibilidades da construção de um material didático para ensino de Matemática para um curso de Agente Comunitário de Saúde nesta modalidade. Este artigo apresenta resultado de uma pesquisa de mestrado: o Caderno Temático Saúde e Números, composto por 10 unidades e um projeto interdisciplinar, cuja finalidade é proporcionar ao estudante o desenvolvimento dos conhecimentos matemáticos de forma interdisciplinar, permitindo uma formação integral do cidadão. Além disso, espera-se que os professores possam, a partir deste, produzir seu próprio material didático.
\end{abstract}

Palavras-chave: PROEJA. Matemática. Saúde. Material Didático.

\begin{abstract}
With the recent inclusion of youth and adults in the federal system of vocational and

\footnotetext{
* Mestre em Ensino de Ciências e Matemática pela Pontifícia Universidade Católica de Minas Gerais (PUC-MG). Professora do Instituto Federal do Sudeste de Minas (IF SUDESTE MG), Campus Rio Pomba, Rio Pomba, MG, Brasil. Endereço para correspondência: Departamento Acadêmico de Matemática, Física e Estatística (DMAFE). Av. Dr. José Sebastião da Paixão s/nº, Bairro Lindo Vale. CEP: 36180-000. Rio Pomba, MG, Brasil. E-mail: paula.reis@ifsudestemg.edu.br.

**Doutora em Educação pela Universidade Estadual de Campinas (UNICAMP). Mestre em Educação Matemática pela Universidade Estadual Paulista (UNESP), Rio Claro. Professora do Mestrado em Ensino de Ciências e Matemática Pontifícia Universidade Católica (PUC), Minas Gerais, MG, Brasil. Endereço para correspondência: Av. Dom José Gaspar, 500, Coração Eucarístico, CEP: 30535-901. Belo Horizonte, MG, Brasil.E-mail: egazire@terra.com.br.
} 
technological education, through the PROEJA (Program to Integrate Youth and Adults in Basic Education, in Federal Institutions of Education, Science and Technology), there was a need to investigate the possibilities of creating educational material for teaching a mathematics course for Community Health Agents. This article presents the results of a sudy: the Notebook theme "Health and Figures", comprising 10 units and an interdisciplinary project whose aim is to provide the student with the development of mathematical knowledge in an interdisciplinary way, allowing an integral formation of the citizen. Moreover, it is expected that teachers can, from this, produce their own materials.

Keywords: PROEJA. Mathematics. Health. Textbooks.

\section{O PROEJA: conhecendo o cenário}

As instituições de Educação Profissional e Tecnológica (EPT) iniciaram a inserção regular da Educação de Jovens e Adultos na rede federal por meio da implantação do PROEJA (Programa de Integração à Educação Básica na Modalidade Educação de Jovens e Adultos), pelo decreto 5.840/2006. Posteriormente, o programa foi fortalecido com Documento Base do PROEJA (BRASIL, 2007), cuja finalidade foi enfrentar as "descontinuidades e o voluntarismo que marcam a EJA no Brasil” (MOURA, 2006, p.62) e integrar a formação profissional à Educação Básica, contribuindo para a evolução socioeconômica de jovens e adultos. Segundo o Documento Base (BRASIL, 2007), a implantação do PROEJA é justificada pela baixa expectativa de inclusão de jovens e adultos de classes populares no sistema público de EPT e as experiências isoladas de algumas dessas instituições de nessa modalidade.

Conforme o Parecer 11/2000 (BRASIL, 2002) a EJA, como modalidade, deve ser entendida, trabalhada e incorporada no sentido lato da palavra. Para o documento:

O termo modalidade é diminutivo latino de modus (modo,
maneira) e expressa uma medida dentro de uma forma própria
de ser. Ela tem, assim, um perfil próprio, uma feição especial
diante de um processo considerado como medida de
referência. Trata-se, pois, de um modo de existir com
característica própria (BRASIL, 2002, p. 26, grifo do autor).

O Documento Base (BRASIL, 2007) reafirma o referido parecer, advertindo que a EJA trabalha com sujeitos marginais ao sistema, com atributos sempre acentuados em consequência de alguns fatores adicionais como raça/ 
etnia, cor, gênero, assim como trabalhadores informais, emblemáticos representantes das múltiplas apartações que a sociedade brasileira, excludente, promove para grande parte da população desfavorecida econômica, social e culturalmente.

O PROEJA, de acordo com Moura (2006), surge frente a essa realidade com uma proposta de contemplar o público da EJA e inseri-lo na rede federal de Educação, promovendo, assim, a elevação de escolaridade unida à profissionalização, no sentido de contribuir para "a integração sociolaboral de forma gratuita, igualitária e universal". Diante desta proposta, o autor ainda destaca o foco desta formação: a "perspectiva precisa ser, portanto, de formação na vida e para vida e não apenas do mercado ou para ele." (MOURA, 2006, p.8-10).

\section{O enredo: as concepções, os princípios e a heterogeneidade}

O Documento Base do PROEJA (BRASIL, 2007) fundamenta-se na proposta de uma expansão da oferta pública de Educação Básica unida à Educação Profissional, visando à formação integral do cidadão, de forma social e igualitária.

Porém, para que esta proposta seja realmente colocada em prática, tornase necessário o entendimento das peculiaridades, princípios e concepções da EJA que auxiliarão na caracterização do PROEJA.

Além disso, para Moura (2006) a formação integral, assumida como característica marcante do PROEJA, tem como finalidade a superação histórica presente na Educação brasileira entre teoria e prática; cultura geral versus cultura técnica. Esta dualidade torna-se mais acentuada ao deparar-se com as desigualdades e exclusões sociais. Assim, no Documento Base do PROEJA (BRASIL, 2007), é evidenciada a necessidade de se ter formação norteada pela prática social vivenciada pelo estudante durante sua formação e preparação para a vida, consolidada pela formação científica, humanística e tecnológica, possibilitando a consumação dos fundamentos para o amadurecimento político, social, cultural, econômico e no mundo do trabalho, visando à continuidade de estudos como objetivo e não como finalidade em si mesma.

Ainda, de acordo com Moura (2006), a característica dos cursos integrados é a capacidade de proporcionar um vínculo estreito entre a formação básica e a formação profissional. Os estudantes matriculados em cursos de PROEJA estarão inseridos em cursos técnicos integrados ao Ensino Médio com 
carga horária mínima de 2400 horas (BRASIL, 2007), recebendo, portanto, o mínimo de 1200 horas de formação geral e a carga horária mínima estabelecida no Catálogo Nacional de Cursos Técnicos de formação profissional técnica. Machado (2006) elucida caminhos para a construção desse currículo e o alcance de um novo aprendizado por meio de conscientização da necessidade de harmonizar conteúdos, inserindo novos saberes em suas práticas e coordenação temporal das ações didáticas, de considerar as demandas de compartilhamento, cooperação e estruturação do trabalho pedagógico de forma interdisciplinar.

Além disso, na leitura do Documento Base do PROEJA (BRASIL, 2007), percebe-se que este programa tem como princípios de consolidação de sua política os fundamentos da EJA, do Ensino Médio e dos cursos de formação profissional: a inclusão; a inserção orgânica da modalidade EJA integrada à Educação profissional nos sistemas públicos; a ampliação do direito à Educação Básica; o trabalho como princípio educativo, a ação transformadora no mundo, para si e para os outros; a pesquisa como fundamento da formação do sujeito envolvido, contribuindo para sua autonomia intelectual e as condições geracionais, de gênero, de relações étnico-raciais como base da formação humana e dos modos de produção das identidades sociais.

No entanto, até o presente momento não há nenhum material didático editado para o ensino de Matemática específico para cursos de PROEJA, uma vez que se diferenciam dos de Educação Básica e Técnica. Foram encontrados alguns trabalhos em etapa de discussão e organização de apostilas temáticas, como as elaboradas para o curso de edificações do Instituto Federal do Espírito Santo, sob a coordenação de Freitas e Jordane (2009).

Nesse sentido, Hotz (2008) questiona se a formação pretendida pelo PROEJA será capaz de prover os alunos de conhecimentos que possam ampliar suas visões frente à realidade social e econômica atual e, até mesmo, intervir no sistema capitalista. Para a autora:

Nesse contexto econômico e social, percebemos que as funções do PROEJA são limitadas à própria lógica do capital, e para se reduzir significativamente a pobreza e a marginalidade, consequências deste modo de produção, seria necessário a sua negação e a construção de uma nova sociedade. (HOTZ, 2008, p.11).

Porém, nessa perspectiva, a autora ainda enfatiza sobre as "possibilidades do programa em desvelar as contradições presentes no sistema capitalista" (HOTZ, 2008, p.11). Destacando-se os papéis reparador, equalizador e 
qualificador do PROEJA, tendo ele as funções de oferecer os conhecimentos de uma educação geral e os de profissionalização, diminuir as diferenças, concedendo aos jovens e adultos a oportunidade de ingressar no mundo do trabalho e transmitir conhecimentos gerais que permitam aos trabalhadores adaptaremse às mudanças produtivas, estando flexíveis às possibilidades e exigências do mundo globalizado.

A partir de 2006, com o anseio de implantar e estabelecer o PROEJA significativamente nas instituições de ensino, o Ministério da Educação (MEC) e a Secretaria de Educação Profissional e Tecnológica (SETEC) iniciam ações relativas a esta modalidade de ensino e, desde então, o governo federal, por meio da SETEC/MEC, tem apoiado ações relacionadas ao PROEJA, por exemplo, a bolsa auxílio ao educando, a produção de materiais didáticos específicos para os cursos nesta modalidade, a capacitação de professores e servidores da rede federal e diálogos educativos envolvendo, também, representantes de estados e municípios.

Assim, na perspectiva de assegurar a formação humana, com acesso ao universo de saberes e conhecimentos científicos e tecnológicos integrados a uma formação profissional que permita compreender o mundo, compreender-se no mundo e nele atuar na busca da melhoria das próprias condições de vida e da construção de uma sociedade socialmente justa, propôs-se a elaboração de um material didático específico para o Curso Técnico em Agente Comunitário de Saúde (ACS) na modalidade PROEJA.

\section{A trama: o Caderno Temático}

O primeiro passo para a construção do Caderno Temático foi a elaboração de um programa de Matemática para o Curso de Técnico em ACS na modalidade PROEJA, visto que, nos documentos que regem essa modalidade, como já mencionado, não há uma definição dos conteúdos matemáticos que devem ser trabalhados. Até então, via-se uma tentativa, por parte dos professores, de adequar o conteúdo do Ensino Médio à carga horária e especificidade do PROEJA.

Para essa construção foram realizadas entrevistas coletivas semiestruturadas, gravadas em áudio e imagem, abrangendo sete docentes com formação na área de saúde e 5 discentes do curso que já trabalhavam como ACS. Embasado na análise destas e nas diretrizes da Educação Básica e Tecnológica, foi elaborado um programa de Matemática visando à formação do ser humano na perspectiva de formação integral do cidadão. Frankenstein (2005) 
ressalta o papel do professor de Matemática ao apresentar os aspectos da Matemática, positivos e negativos, destacando a importância do raciocínio quantitativo no desenvolvimento de consciência crítica e, consequentemente, as ansiedades trazidas pelo educando.

As unidades elaboradas, portanto, estão diretamente relacionadas à área de saúde. O material é organizado em fichas que poderão ser aplicadas sem ordem pré-estabelecida. O programa selecionado encontra-se na quadro 1, abaixo, juntamente com os temas das unidades e seus objetivos:

\begin{tabular}{|c|c|c|}
\hline \multicolumn{3}{|c|}{ PROPOSTA DE TEMAS PARA O CADERNO TEMÁTICO PARA CURSO TÉCNICO ACS - PROEJA } \\
\hline Unidade & Conteúdos & Objetivos \\
\hline $\begin{array}{l}\text { 1- Dinheiro e } \\
\text { Saúde }\end{array}$ & $\begin{array}{l}\text { Operações com } \\
\text { números decimais }\end{array}$ & $\begin{array}{l}\text { Compreender, aplicar e resolver as operações de adição, } \\
\text { subtração, multiplicação e divisão de números decimais. }\end{array}$ \\
\hline $\begin{array}{l}\text { 2- Números e } \\
\text { operações: } \\
\text { contextualizando } \\
\text { saberes }\end{array}$ & $\begin{array}{l}\text { Porcentagem e } \\
\text { leitura e escrita de } \\
\text { números }\end{array}$ & $\begin{array}{l}\text { Ler e escrever grandezas. } \\
\text { Compreender o conceito e as representações de porcentagens. } \\
\text { Resolver situações-problema envolvendo porcentagens. }\end{array}$ \\
\hline $\begin{array}{l}\text { 3- Analisando os } \\
\text { números da gripe } \\
\text { suína }\end{array}$ & $\begin{array}{l}\text { Leitura e escrita de } \\
\text { números, Média } \\
\text { aritmética }\end{array}$ & $\begin{array}{l}\text { Ler e escrever grandezas. } \\
\text { Compreender o conceito e a aplicação de média aritmética. } \\
\text { Calcular médias aritméticas. }\end{array}$ \\
\hline $\begin{array}{l}\text { 4- Conhecendo a } \\
\text { obesidade através } \\
\text { dos números }\end{array}$ & $\begin{array}{l}\text { Leitura e } \\
\text { interpretação de } \\
\text { gráficos e grandezas }\end{array}$ & $\begin{array}{l}\text { Diferenciar as unidades de medidas. } \\
\text { Transformar as unidades de medidas. } \\
\text { Ler e interpretar tabelas e gráficos estatísticos. } \\
\text { Conhecer, compreender e aplicar os diversos gráficos } \\
\text { estatísticos. }\end{array}$ \\
\hline $\begin{array}{l}\text { 5- } \mathrm{O} \text { aquecimento } \\
\text { global em números }\end{array}$ & $\begin{array}{l}\text { Números inteiros, } \\
\text { razão e proporção }\end{array}$ & $\begin{array}{c}\text { Conhecer a notação científica. } \\
\text { Comparar e operar com números inteiros. } \\
\text { Introduzir ao ambiente do aluno situações-problema } \\
\text { envolvendo razões e proporções. }\end{array}$ \\
\hline $\begin{array}{l}\text { 6- Frações de saúde } \\
\text { para uma vida } \\
\text { melhor }\end{array}$ & Frações & $\begin{array}{c}\text { Ler, compreender e comparar frações. } \\
\text { Dominar as operações envolvendo frações. } \\
\text { Compreender e aplicar o conceito de frações equivalentes. }\end{array}$ \\
\hline $\begin{array}{l}\text { 7- Desvendando } \\
\text { bulas de } \\
\text { medicamentos }\end{array}$ & $\begin{array}{l}\text { Razão e proporção, } \\
\text { sequências } \\
\text { numéricas }\end{array}$ & $\begin{array}{c}\text { Compreender as definições de razão e proporção, bem como } \\
\text { suas propriedades. } \\
\text { Diferenciar grandezas diretamente e inversamente } \\
\text { proporcionais. } \\
\text { Resolver situações-problema em que se apliquem regra de três. } \\
\text { Oportunizar a discussão sobre sequências. }\end{array}$ \\
\hline $\begin{array}{l}\text { 8- Saúde em } \\
\text { sólidos } \\
\text { geométricos }\end{array}$ & Geometria espacial & $\begin{array}{c}\text { Reconhecer os sólidos geométricos e identificar seus } \\
\text { elementos. } \\
\text { Calcular área de figuras planas e o volume dos sólidos } \\
\text { estudados. }\end{array}$ \\
\hline $\begin{array}{l}\text { 9- Conhecendo a } \\
\text { realidade do PSF } \\
\text { no Brasil }\end{array}$ & $\begin{array}{l}\text { Coordenadas } \\
\text { cartesianas e noções } \\
\text { de análise } \\
\text { combinatória }\end{array}$ & $\begin{array}{l}\text { Compreender a representação no plano cartesiano. } \\
\text { Localizar pontos no plano cartesiano e aplicar essa } \\
\text { representação a situações cotidianas. } \\
\text { Resolver situações-problema envolvendo noções de análise } \\
\text { combinatória. }\end{array}$ \\
\hline $\begin{array}{l}\text { 10- Em função da } \\
\text { saúde das crianças }\end{array}$ & Funções & $\begin{array}{c}\text { Compreender o conceito de função. } \\
\text { Traçar e interpretar o gráfico de uma função. } \\
\text { Encontrar os intervalos de crescimento, decrescimento e as } \\
\text { raízes de uma função. }\end{array}$ \\
\hline $\begin{array}{c}\text { PROJETO: } \\
\text { Matemática e a } \\
\text { saúde das crianças }\end{array}$ & $\begin{array}{l}\text { Unidades de medida, } \\
\text { coordenadas, } \\
\text { porcentagens, } \\
\text { gráficos e função. }\end{array}$ & $\begin{array}{c}\text { Organizar e registrar as ideias, construir e analisar gráficos } \\
\text { criticamente. }\end{array}$ \\
\hline
\end{tabular}

Quadro 1 - Unidades e conteúdos que compõem o Caderno Temático

Fonte: Caderno temático 
Pretende-se, por meio da organização destas unidades, proporcionar ao educador a possibilidade de criação de novas investigações e experimentações, relacionando diversas disciplinas, como Física, Química, Educação Física, entre outras, de forma a contribuir para a formação do desenvolvimento democrático do aluno do PROEJA, como cidadão crítico e consciente, como afirma Skovsmose (2001).

Portanto, para a elaboração desta proposta de Caderno Temático, foram consultados, além da bibliografia já apresentada, alguns materiais didáticos, como, por exemplo, Dante (2008), Iezzi, Dolce e Machado (2000), Grasseschi, Andretta e Silva (1999), Brasil (2008), Gomes et al (2007). A respeito deste tipo de consulta, Fonseca (2007) afirma ser pequena a produção didática para ensino de Matemática para EJA e, aqui, especialmente para o PROEJA tem-se como alternativa "recorrer a materiais que, embora elaborados originalmente visando o público adolescente ou mesmo infantil, podem ser adaptados ao trabalho com alunos adultos." (FONSECA, 2007 p.100).

\section{0 ator principal - o aluno}

A partir dessa realidade, foi criado um caderno de Matemática que fornecesse elementos para a formação integral do estudante do Curso Técnico em ACS - PROEJA. O Caderno Temático foi nomeado como Saúde e Números, cuja proposta é aproximar jovens e adultos do ambiente escolar e do mundo do trabalho, especificamente relacionando a Matemática à área da saúde. Conhecimentos relacionados à atuação do ACS e à comunidade serão abordados por meio de textos e reportagens que possibilitam o trabalho com investigações e resolução de problemas.

Foi proposto, então, um material flexível à criação de novas investigações, resolução de problemas e experimentações, sob a proposta interdisciplinar, envolvendo as mais variadas disciplinas, procurando trazer para a sala de aula do PROEJA: "uma experiência em profundidade, uma oportunidade de conhecer e delinear as dificuldades, de conhecer as capacidades e limitações do conhecimento matemático que os estudantes possuem." (HUAMAN HUANCA, 2008, p. 4).

Para tanto, neste Caderno Temático, o início de cada unidade se dá com a leitura de textos atuais da área de saúde, objetivando uma reflexão a respeito do bem-estar da população brasileira. Esta estratégia visa a incentivar e valorizar o hábito de leitura e escrita dos estudantes, bem como aproximá-los de textos 
informativos, instigando alunos e professores a um conhecimento interdisciplinar e a uma ação para com a comunidade escolar, características do trabalho do ACS.

Outra preocupação vinculou-se à valorização de diferentes gêneros textuais, a fim de apresentar as informações da área de saúde de forma variada e contextualizada, aproximando-as dos conhecimentos matemáticos. Neste sentido, Schneuwly e Dolz (1999) destacam a importância de ações que incentivem a produção, compreensão, interpretação e/ou memorização de diferentes conjuntos de enunciados, orais ou escritos, para oportunizar diferentes ações de linguagem. Essa variação fica mais evidente quando verificamos a distribuição das unidades do Caderno Temático entre os gêneros de linguagem utilizados na sua construção (Quadro 2):

\begin{tabular}{|c|c|}
\hline Unidade & Gêneros de Linguagem \\
\hline 1- Dinheiro e Saúde & Panfleto publicitário \\
\hline 2- Números e operações: contextualizando saberes & Notícia de site \\
\hline 3- Analisando os números da gripe suína & Notícia de revista \\
\hline 4- Conhecendo a obesidade através dos números & Notícia de site e Texto histórico \\
\hline 5- $\mathrm{O}$ aquecimento global em números & Notícia de site e Música \\
\hline 6- Frações de saúde para uma vida melhor & Receita \\
\hline 7- Desvendando bulas de medicamentos & Bula de remédios \\
\hline 8- Saúde em sólidos geométricos & Texto narrativo e Texto informativo \\
\hline 9- Conhecendo a realidade do PSF no Brasil & Notícia de site e mapa \\
\hline 10- Em função da saúde das crianças & Texto Informativo \\
\hline Encarte & Poesia \\
\hline
\end{tabular}

Quadro 2 - Gêneros de linguagens predominantes nas unidades do Caderno Temático Fonte: Caderno Temático

Além disso, para efetivar o trabalho a ser desenvolvido nesse material, o mesmo foi subdividido em seções que permearão todas as unidades, identificadas, cada uma, com um ícone correspondente (Quadro 3): 


\begin{tabular}{|l|l|}
\hline \multicolumn{2}{|c|}{ AS SEÇOEES } \\
\hline Icone & Nome \\
\hline & Discutindo o texto \\
\hline & Dividades \\
\hline & Dialogando com a Matemática \\
\hline
\end{tabular}

Quadro 3 - Ícones e nomes das seções que compõem o Caderno Temático Fonte: Caderno Temático

A seção Discutindo o texto propõe uma ampliação das ideias apresentadas no texto inicial de cada atividade. Conforme afirma Klüsener (2004), a leitura realiza-se plenamente quando se é capaz de interpretar as representações emergentes do texto, da palavra, do símbolo ou do mundo.

Portanto, a partir da leitura do texto e da socialização das questões desta seção, o aluno poderá analisar criticamente o tema e relacioná-lo com as situações do mundo moderno, em especial com seu município e seu ambiente de trabalho. Com esta proposta, espera-se que o estudante tenha uma melhor visão da realidade e, consequentemente, do assunto estudado na unidade, pois embasado nos conhecimentos de Freire (2001), "a leitura do mundo precede a leitura das palavras" (FREIRE, 2001, p.11).

Na etapa seguinte, Atividades, o estudante estará ampliando seus conhecimentos matemáticos por meio da resolução de situações-problema, extraídas do texto inicial e da prática de um ACS. Corroborando essas propostas, Klesser (2006) afirma que: 
Em uma metodologia centrada na resolução de problemas, o aluno tem a possibilidade de colocar em ação seus conhecimentos e desenvolver a capacidade para ler e gerenciar informações expressas de diferentes maneiras, ampliando sua visão acerca da Matemática. (KLESSER, 2006, p. 113).

Além disso, a abordagem interdisciplinar é um dos focos da proposta desse material, e está ressaltada na seção Dialogando com outras áreas do conhecimento. Sendo assim, foi criada uma seção específica, objetivando propiciar um diálogo entre as várias áreas do conhecimento, a Matemática e a saúde. A partir dos questionamentos apresentados, poder-se-á criar novas atividades e projetos de intervenção, conforme algumas indicações contidas nas fichas do professor. Nessa perspectiva, Fonseca (2007) assegura que este tipo de abordagem pode ajudar na construção de novos instrumentos cognitivos e novos significados, por meio do cruzamento de saberes traduzidos no diálogo, na discussão das divergências e confluências, ultrapassando as fronteiras entre as disciplinas.

É interessante, assim, que, antes de iniciar o trabalho com cada unidade, haja uma discussão com os demais professores do curso, a fim de que o diálogo entre as disciplinas ocorra de forma contínua e produtiva: "O ensino de Matemática, portanto, deve criar condições para que o aluno reconheça sua capacidade de construir conhecimento e proceder continuamente como pesquisador." (KLÜSENER, 2004, p.203).

Para tanto, para efetivar o trabalho com a Matemática, foi incluída a seção Dialogando com a Matemática, que apresenta orientações e, em seguida, atividades a serem exploradas por professores e alunos, para permitir uma aprendizagem significativa dos conteúdos apresentados, tomando como meta a alfabetização matemática do jovem e adulto, que, conforme Klüsener (2004), se dá por meio do entendimento e da compreensão do que se lê e se escreve em Matemática, incluindo as noções iniciais de Aritmética, Geometria, Lógica e Álgebra, sem perder a dimensão social e cultural do processo de ensinoaprendizagem. Esta concepção é reforçada por Fonseca (2007), que considera “o ensino aprendizagem da Matemática na EJA como um processo discursivo, de negociação de significados constituídos na relação com o objeto, percebido, destacado, re-enfocado pelo sujeito" (FONSECA, 2007, p.86).

Após o diálogo com a Matemática, é sugerido o aprofundamento dos 
conceitos abordados por meio de atividades a ser desenvolvidas pelos estudantes na seção Ampliando os conhecimentos, onde os estudantes terão um espaço para retomar, verificar e exercitar os conhecimentos matemáticos trabalhados anteriormente, por meio de uma metodologia que possa, de acordo com Klesser (2006), "sustentar-se em ações que envolvem o aluno ativamente no processo de aprender, desafiando-o a formular e reformular hipóteses e verbalizar suas concepções acerca do que está sendo proposto - ações importantes na construção do conhecimento matemático." (KLESSER, 2006, p. 113).

Já segundo o Documento Base do PROEJA (BRASIL, 2007), os princípios e concepções desta modalidade têm, como objetivo, permitir aos estudantes jovens e adultos a inserção no mundo do trabalho e, consequentemente, no mundo globalizado. Pretende-se, então, com a seção Investigando com a ajuda da tecnologia, levar para a sala de aula de Matemática a possibilidade de incorporação da tecnologia ao cotidiano destes alunos. Nela, os estudantes terão contato direto com a tecnologia, utilizando a calculadora, o computador e várias de suas ferramentas, por exemplo: softwares, planilha de dados, sites, vídeos, e-mails etc.

Segundo Abrantes (1996), as atividades com a Matemática devem ter significado e cativar o interesse do aluno. Nesta perspectiva, encerra-se este material com a seção Projeto, que traz um projeto a ser desenvolvido durante o semestre ou ano letivo.

$\mathrm{O}$ autor ainda ressalta as contribuições evidenciadas no trabalho com projetos: “[...] (I) assumir responsabilidades, (II) trabalhar de modo cooperativo e (III) enfrentar situações que requerem persistência.” (ABRANTES, 1996, p.42).

Nessa parte, então, é realizada uma proposta aberta, na qual o aluno se torna ator da sua própria formação, conquistando sua autonomia e ampliando seus conhecimentos matemáticos e do mundo do trabalho.

\section{0 outro protagonista: o apoio pedagógico ao professor}

Além do material do estudante, é proposto o Caderno do Professor, apresentado em forma de CD. Nele, encontram-se, além das atividades apresentadas no material dos alunos, fichas com orientações metodológicas referentes a cada unidade. Também, são disponibilizados vídeos, selecionados para ampliação dos conhecimentos apresentados em cada unidade, e dois softwares livres para uso de docentes e discentes: o Winplot e o Geogebra. 
Neste suporte, permite-se ao professor reproduzir as atividades para um maior número de turmas ou alunos, além de criar novas atividades a partir das já existentes.

Para auxiliar o trabalho do professor, ao final de cada atividade, são apresentadas algumas orientações metodológicas (Quadro 4), por meio de uma ficha denominada Conversando com o educador, a fim de contribuir para a organização e o desenvolvimento de seu trabalho em sala de aula.

\begin{tabular}{|c|c|}
\hline \multicolumn{2}{|r|}{ Orientações Metodológicas } \\
\hline Conteúdo & $\begin{array}{l}\text { Apresenta o tema matemático que norteia as discussões propostas na unidade. A } \\
\text { ficha poderá abordar outros conteúdos, mas aqui o professor pode verificar a } \\
\text { principal temática da unidade }\end{array}$ \\
\hline Metodologia & $\begin{array}{l}\text { Sugere alguns procedimentos que podem facilitar e enriquecer o trabalho na } \\
\text { sala de aula. }\end{array}$ \\
\hline Tempo estimado & $\begin{array}{l}\text { Como em toda disciplina, é necessário planejar o tempo para que a unidade seja } \\
\text { executada por completa. Com a orientação de Tempo Estimado, o professor } \\
\text { pode utilizar-se do material em cursos bimestrais, modulares, semestrais ou } \\
\text { anuais, sem prejuízo para o aluno e para o registro escolar. }\end{array}$ \\
\hline $\begin{array}{l}\text { Orientações } \\
\text { Complementares }\end{array}$ & $\begin{array}{l}\text { Apresenta propostas de novas atividades e dinâmicas de sala de aula, a fím de } \\
\text { enriquecer as aulas de Matemática, integrando-as ao trabalho com outras } \\
\text { disciplinas. }\end{array}$ \\
\hline Avaliação & $\begin{array}{l}\text { Avaliar é uma forma de acompanhar o jovem e adulto em seu processo de } \\
\text { aprendizagem. Portanto, no tópico Avaliação, são sugeridas diferentes formas } \\
\text { de avaliação dos conteúdos abordados na unidade trabalhada. }\end{array}$ \\
\hline Observações & $\begin{array}{l}\text { Traz a explanação de algumas seções, quando necessário, e a indicação de } \\
\text { alguns vídeos, links e softwares que poderão contribuir para a ampliação das } \\
\text { discussões sobre o tema proposto na unidade. }\end{array}$ \\
\hline Bibliografia & $\begin{array}{l}\text { Ao final das orientações, é apresentada uma listagem de outros materiais, como } \\
\text { livros, periódicos, sites, entre outros, a fim de contribuir com trabalho do } \\
\text { docente em sala de aula e também com seu crescimento profissional e } \\
\text { intelectual. }\end{array}$ \\
\hline
\end{tabular}

Quadro 4 - Ficha de Orientações Metodológicas

Fonte: Material para o professor - CD Saúde e Números

Inicialmente, essas fichas de apoio metodológico estruturam o trabalho do professor, dando maior segurança em um primeiro contato com um material didático diferenciado e contextualizado. Posteriormente, oportunizam a criação de novas possibilidades de utilização e organização de novas metodologias a partir do material já existente. Torna-se importante que o professor avalie constantemente o material, adaptando-o conforme sua realidade cotidiana.

Formulada a proposta deste material didático, tornou-se fundamental passar à próxima etapa: o contato dos estudantes com este novo recurso para o 
ensino da Matemática, a fim de verificar a opinião dos estudantes sobre o mesmo e, consequentemente, fazer as devidas sugestões.

\section{0 desenrolar da história}

Para aplicação das atividades foram escolhidas duas turmas do curso de ACS na modalidade PROEJA, do Instituto Federal do Sudeste de Minas Campus Rio Pomba, campus pioneiro na implantação deste curso no estado de Minas Gerais: uma turma cursando o $2^{\circ}$ período e a outra o $4^{\circ}$ quarto e último período do curso, respectivamente com 18 e 24 alunos matriculados e frequentando as aulas.

Esta escolha se deu a fim de permitir uma visão mais ampla da aplicação das atividades (visto que foi aplicada para duas turmas distintas: uma que está começando o curso e outra em etapa de conclusão), bem como a aceitação e adequação das mesmas a um público mais heterogêneo.

A instituição onde ocorreu a aplicação possui cinco laboratórios de informática, equipamentos de projeção e uma coordenação específica para área de Matemática. O curso de ACS possui dez professores, sendo um deles o coordenador do curso, todos com graduação e pós-graduação, porém nenhum destes possui formação específica para EJA ou PROEJA.

A aplicação das unidades teve como proposta norteadora o trabalho coletivo, a interdisciplinaridade e a resolução de problemas, com o objetivo de proporcionar aos estudantes uma visão aplicada e crítica do conhecimento matemático relacionada à área da saúde.

Para a coleta e análise de dados, durante a aplicação das atividades, foi utilizada a técnica de observação, embasada em Lüdke e André (1986), que afirmam que:

A observação direta permite também que o observador chegue mais perto da "perspectiva do sujeito", um importante alvo nas abordagens qualitativas. Na medida em que o observador acompanha in loco as experiências diárias dos sujeitos, pode tentar aprender sua visão de mundo, isto é o significado que eles atribuem à realidade que os cerca e às suas próprias ações. (LÜDKE; ANDRÉ, 1986, p. 26).

Nesta perspectiva, o mais importante é a reação, a decisão e a atitude dos estudantes diante das situações-problema apresentadas. Portanto, a fim de 
tornar a observação válida e fidedigna, foram feitos planejamento e uma ficha para o registro das observações no formato de diário de campo.

Ao final de cada um dos encontros, as atividades foram recolhidas e, posteriormente, analisadas uma a uma, com o objetivo de se obter maiores detalhes sobre a compreensão dos estudantes acerca do estudado.

\section{O grande final ou início para uma trilogia}

Após quatro anos da implantação do PROEJA na rede federal, ainda verificam-se os resquícios do processo de implantação do programa por meio de decretos. É notável a sobreposição de propostas e documentos, o desconhecimento da legislação do programa e a formação tardia dos professores para trabalhar com essa modalidade na rede federal.

Torna-se necessário explicitar que ainda há poucos estudos sobre a EJA e, principalmente, sobre o PROEJA. A luta de professores, alunos e secretarias do Ministério da Educação pela transformação desse programa em uma política pública tem sido uma grande possibilidade para a permanência e evolução da modalidade. O incentivo para ampliação dos cursos técnicos PROEJA, a produção de material didático e os cursos de especialização Lato sensu específicos para formação dos professores do PROEJA têm contribuído para esse processo.

Torna-se fundamental, portanto, que docentes, discentes e servidores da rede federal façam um estudo detalhado do Documento Base do PROEJA (2007), em especial dos princípios e concepções desse programa, a fim de reconhecer as semelhanças e diferenças entre a EJA e o PROEJA. Assim, será possível a incorporação do PROEJA como proposta sólida do projeto político pedagógico da instituição, trazendo, como consequência, melhor qualidade de ensino e maior formação crítica para os jovens e adultos da comunidade educativa.

O PROEJA tem carga horária mínima pré-estabelecida para a formação técnica e para formação básica, porém, percebe-se uma carga horária reduzida, e este fato atinge também a disciplina de Matemática. Devido a isso, os conteúdos fundamentais para a formação de um Técnico em ACS foram listados a partir da indicação dos professores responsáveis pela formação técnica dos estudantes.

Essa nova proposta de conteúdos possibilitou um diálogo entre várias áreas do conhecimento e foi estruturada em um Caderno Temático Saúde e Números.

Portanto, a proposta de um caderno contextualizado, composto por textos de diferentes gêneros textuais, busca a aproximação dos jovens e adultos com a 
atualidade, o hábito da leitura e os conteúdos matemáticos presentes no seu cotidiano. Com esta possibilidade de aproximar os estudantes, a leitura e a Matemática, espera-se o desenvolvimento das habilidades matemáticas e a formação de cidadãos funcionalmente alfabetizados. (FONSECA, 2004).

A organização do material em seções, com atividades interdisciplinares, envolvendo os estudantes em atividades práticas e aproximando-os do uso da tecnologia teve aprovação dos mesmos.

A aplicação das atividades mostrou-se como uma potencialidade além das expectativas da pesquisa. Das três atividades aplicadas para mais de cinquenta estudantes, apenas uma dupla não esteve favorável à proposta, isto porque, independentemente da modalidade, existe a preocupação com o vestibular, tornando necessária essa discussão nas salas de aula de PROEJA. Nesse sentido, foram reformuladas unidades para estudo de temas como o plano cartesiano, funções, análise combinatória, geometria espacial e geometria analítica. Em seguida foram revisadas as fichas de orientação ao professor, de forma a flexibilizar o tempo para a utilização do Caderno Saúde e Números, possibilitando, sempre que possível, o enriquecimento das aulas de Matemática para a formação emancipatória e crítica dos jovens e adultos.

Também, a diversidade de gêneros de linguagem do Caderno Temático chamou a atenção de estudantes e professores, além do que os professores de disciplinas parceiras à Matemática relataram a importância das atividades para a consolidação da formação integrada proposta pelo curso.

As fichas Conversando com o educador consolidam o compromisso do material em contribuir com o trabalho do professor de Matemática, permitindolhe o conhecimento detalhado de cada unidade e, o que é essencial, a reformulação da proposta ou criação de novas atividades. Estas fichas procuram proporcionar segurança e consistência ao trabalho do professor e, ao mesmo tempo, instigamno a ultrapassar os limites do material e até mesmo criar seu próprio.

O Caderno Temático Saúde e Números foi submetido ao Ofício Circular 192/09 DPEPT/SETEC/MEC (BRASIL, 2009) e aprovado sem proposta de alteração, pela SETEC (BRASIL, 2010). A partir desta aprovação, a SETEC financiará a publicação e distribuição do Caderno Temático Saúde e Números para todas as instituições federais de Educação Tecnológica - Institutos, Uneds, CEFETs e Escolas Agrotécnicas.

O modelo de análise, seleção e abordagem de tópicos matemáticos podem possibilitar aos professores de Matemática de outros cursos de PROEJA a elaboração de suas ementas e, posteriormente, de seus materiais didáticos, 
contribuindo para uma aprendizagem matemática efetiva dos alunos do curso de PROEJA.

Constata-se, ainda, que dentro de um mesmo curso podem ser construídos vários cadernos temáticos interligados pela área de formação técnica e pela organização de um currículo integrado. O trabalho colaborativo na construção do material estreita as relações entre as disciplinas, favorecendo o planejamento coletivo e, consequentemente, buscando a formação integral dos jovens e adultos envolvidos no processo.

Espera-se que, com este trabalho e com a divulgação do Caderno Temático Saúde e Números, os educadores dos diversos cursos técnicos na modalidade PROEJA possam usufruir desse material para a formação integral dos jovens e adultos de seus cursos. Por conseguinte, almeja-se, ainda, que, num futuro não muito distante, os educadores do PROEJA construam interdisciplinarmente materiais específicos para cada curso, reconhecendo, assim, a necessidade da formação técnica, básica e social do profissional, fazendo das diferenças a possibilidade para a criação de uma nova proposta de ensino e de uma aprendizagem significativa para um cidadão crítico e transformador da sociedade.

\section{Referências}

ABRANTES, P. Trabalho de Projecto e Aprendizagem Matemática. In: CONGRESSO BRASILEIRO DE AÇÃO PEDAGÓGICA, 2., 1996, Belo Horizonte. Anais... Belo Horizonte: Secretaria Municipal de Educação, 1996.

BRASIL. PARECER CEB 11/2000. In: SOARES, L.Diretrizes Curriculares Nacionais: Educação de Jovens e Adultos. Rio de Janeiro: DP\&A, 2002.

BRASIL, Ministério da Educação e do Desporto. Secretaria de Educação Média e Tecnológica. Decreto 5.840, de 23 de julho de 2006. Institui, no âmbito federal, o Programa de Integração da Educação Profissional com a Educação Básica na Modalidade de Educação de Jovens e Adultos - PROEJA. Brasília: 23 de julho de 2006.

BRASIL, Ministério da Educação e do Desporto. Secretaria de Educação Média e Tecnológica. PROEJA: Programa Nacional de Integração da Educação Profissional com a Educação Básica na Modalidade da Educação de Jovens e Adultos. Educação Profissional Técnica de Nível Médio / Ensino Médio - Documento Base. Brasília: MEC/SETEC, 2007. 
BRASIL, Programa Nacional de Inclusão de Jovens. Os números naturais e suas aplicações. Coleção ProJovem Urbano Oficina 1. Brasília, 2008.

BRASIL, Ministério da Educação e do Desporto. Secretaria de Educação Média e Tecnológica. Ofício Circular n¹92/09 DPEPT/SETEC/MEC. Brasília: MEC, 2009b. Disponível em: <http://www.mec.gov.br>Acesso em: 28 dez. 2009.

BRASIL, Ministério da Educação. Secretaria de Educação Profissional e Tecnológica. Comunicado. Brasília, MEC, 2010. Disponível em: <http://portal.mec.gov.br/ index.php?option=com_content\&view=article\&id=12924:artigos\&catid=190:setec $>$. Acesso em: 01 ago. 2010.

DANTE, L. R. Matemática. São Paulo: Ática, 2008.

FONSECA, M. da C. F. R. (Org.) Letramento no Brasil: habilidades matemáticas. São Paulo: Global, 2004.

FONSECA, M. da C. F. R. Educação Matemática de Jovens e Adultos. 2.ed. Belo Horizonte: Autêntica, 2007.

FRANKENSTEIN, M. Educação Matemática crítica: uma aplicação da epistemologia de Paulo Freire. In: BICUDO, M. A. V. (Org). Educação Matemática. 2.ed. São Paulo: Centauro, 2005.p. 101 - 140.

FREIRE, P. A importância do ato de ler em três artigos que se completam. São Paulo, Cortez: 2001.

FREITAS, R. C. de O. F.; JORDANE, A. Material Didático de Matemática para o PROEJA: Uma construção Colaborativa. In: SINECT - SIMPÓSIO NACIONAL DE ENSINO DE CIÊNCIAS E TECNOLOGIA, 1., 2009, Ponta Grossa. Anais... Ponta Grossa: FUNTEF, 2009, v. 1.p. 948 - 970. Disponível em: <http://www.pg.utfpr.edu.br/ sinect/anasis/artigos/10\%20Ensinode matemática/Ensinodematematica_artigo9.pdf>. Acesso em: 10 jun. 2009.

GOMES et al. Viver, aprender $7^{\mathrm{a}} \mathbf{e} 8^{\mathrm{a}}$ séries. São Paulo: Global, 2007.

GRASSESCHI, M. C. C. ANDRETTA, M. C, SILVA, A. B. S. PROMAT: projeto oficina de matemática. São Paulo: FTD,1999. 4v.

HOTZ, K.G. PROEJA: Limites e possibilidades para a classe trabalhadora. In: SEMINÁRIO DO TRABALHO: TRABALHO, ECONOMIA EEDUCAÇÃO, 6., 2008, Marília-SP. Anais.... Marília: Grafica Massoni, v. 1, 2008. Disponível em: <http:// www.estudosdotrabalho.org/anais6seminariodotrabalho/indice.htm>. Acesso em: 01 jul. 2010. 
HUMAN HUANCA, R. R. Um olhar para a sala de aula a partir da resolução de problemas e modelação matemática. In: SEMINÁRIO EM RESOLUÇÃO DE PROBLEMAS, 1., 2008, Rio Claro. Anais... São Paulo: UNESP, 2008. Disponível em: $<$ http://www.rc.unesp.br/serp/trabalhos.html>. Acesso em: 20 jul. 2010.

IEZZI, G;; DOLCE, O. MACHADO, A. Matemática e realidade. São Paulo: Atual, 2000.

KLESSER, M. C.. Educação de Jovens e Adultos: (dês)construindo saberes nos espaços do aprender e ensinar matemática. Zetetiké: Campinas,v.14, n. 26, p.103 - 121, jul/dez, 2006.

KLÜSENER, R. Ler, escrever e compreender a matemática, ao invés de tropeçar nos símbolos. In: NEVES, I. C. B. et al. (Org.). Ler e escrever: compromisso de todas as áreas. Porto Alegre: Ed. UFRGS, 2004.

LUDKE, M.; ANDRÉ, M. Pesquisa em Educação: Abordagens Qualitativas. São Paulo: EPU, 1986.

MACHADO, Lucília Regina de Souza . PROEJA: O significado socioeconômico e o desafio da construção de um currículo inovador. In: MEC, SEED, TV Escola, Salto para o Futuro. (Org.). PROEJA: Formação técnica integrada ao ensino médio. Rio de Janeiro: MEC, SEED, TV Escola, Salto para o Futuro, 2006, v. 16, p. 36 - 53. Disponível em: <http://tvbrasil.org.br/fotos/salto/series/141327Proeja.pdf>. Acesso em: 07 mar. 2012.

MOURA, D. H. Eja: Formação Técnica integrada ao Ensino Médio. In: MEC, SEED, TV Escola, Salto para o Futuro. (Org.). PROEJA: Formação técnica integrada ao ensino médio. Rio de Janeiro: MEC, SEED, TV Escola, Salto para o Futuro, 2006, v. 16, p. 03 - 23. Disponível em: <http://tvbrasil.org.br/fotos/salto/series/141327Proeja.pdf>. Acesso em: 07 mar. 2012.

SCHNEUWLY, B.; DOLZ, J. Os gêneros escolares: das práticas de linguagem aos objetos de ensino. Revista Brasileira de Educação, Rio de Janeiro, v. 4, n.11, p.5 - 16, Mai./Ago. 1999.

SKOVSMOSE, O. Educação Matemática Crítica: Aquestão da Democracia. Campinas: Papirus. 2001.

\footnotetext{
Submetido em Maio de 2011. Aprovado em Outubro de 2011.
} 